\title{
Participação dos pais e alunos no cenário da gestão democrática
}

\author{
Elione Maria Nogueira Diógenes \\ Universidade Federal de Alagoas, Maceió -AL, Brasil. \\ elionend@uol.com.br
}

Maria das Graças Correia Gomes

Universidade Federal de Alagoas, Maceió -AL, Brasil.

gracac.gomes@hotmail.com

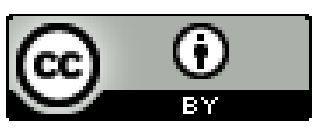

Educação: teoria e prática, Rio Claro, SP, Brasil - elSSN: 1981-8106

Está licenciada sob Licença Creative Common

\section{Resumo}

Este artigo representa o recorte de uma pesquisa realizada no ensino público municipal de Maceió. Investigou-se a participação, no cenário da gestão democrática, do ponto de vista dos pais e alunos. A gestão democrática foi implantada, nesse município, em 1993, três anos antes da LDBEN № 9394/96. O interesse central configurou-se em perceber se os pais e alunos conseguiam se sentir partícipes do processo de democratização da gestão escolar. Daí que se estudou: Libâneo (2004), Gadotti (2002), Paro (2001), Hora (2007) e Tavares (2003) para embasar as categorias gestão democrática e participação. A abordagem metodológica é de base qualitativa, em que se utilizou a técnica de grupos focais com os alunos e os pais. Estes demonstraram os poucos espaços de participação oferecidos, enfatizando as reuniões, em que sua participação está limitada à condição de ouvintes. Os sujeitos da pesquisa lamentam a inércia das famílias diante dos problemas que a escola enfrenta. Para efeito de estrutura, o texto tem duas partes: 1) a historicidade da gestão democrática, os seus princípios e fundamentos em que as autoras abrangem a temática de forma ampla; 2) o relato de como se deu a pesquisa: os sujeitos e os principais procedimentos adotados bem como a análise efetivada.

Palavras-chave: Gestão Democrática. Escola Pública Municipal. Participação.

\section{Participation of parents and students in the scenario of democratic management}

\section{Abstract}

This article is an excerpt from a survey conducted in public education city of Maceió. We investigated whether participation in democratic management scenario, from the point of 
view of parents and students. The democratic management was implemented in this city in 1993, three years before the LDBEN No. 9394/96. The central concern was configured to identify whether parents and students could feel the participants democratization of school management. Hence, we studied: Libâneo (2004), Gadotti (2002), Paro (2001), Hora (2007) and Tavares (2003) to support the categories "democratic management" and "participation". The methodological approach is qualitative basis, which used the technique of focus groups with students and parents. These demonstrated the few opportunities for participation offered, emphasizing the meetings in which their participation is limited to the condition of listeners. The subjects lament the inertia of families facing the problems the school faces. To structure effect, the text has two parts: 1) the historicity of democratic management, its principles and foundations on which the authors cover the subject comprehensively, and 2) an account of how was the research: the subjects and the main procedures adopted and the analysis presented.

Keywords: Democratic Management. Municipal Public School. Participation.

\section{Introdução}

O objetivo deste artigo é o de contribuir para o entendimento das práticas democráticas vivenciadas no ambiente escolar quando se trata da inserção ativa dos pais e dos alunos nesse contexto. Essa realidade é fruto de políticas públicas de corte educativo, oriundas da década de 1990, cuja centralidade encontra-se na importância de fomentar a participação da comunidade na gestão escolar. As lutas sociais dos educadores tornaram possível, na década de 1990, mudanças no rumo da educação nacional com a elaboração da Lei de Diretrizes e Bases para a Educação Nacional № 9394/96 e o Plano Nacional de Educação (2001). Fomentaram, também, a promulgação, em alguns estados brasileiros, de leis regulamentando a Gestão Democrática. Leis que são respeitáveis marcos históricos desse processo, a saber: Lei $\mathrm{n}$ 0 10.576, de 14 de novembro de 1995 (atualizada até a lei n.으 13.990, de 15 de maio de 2012) que foi sancionada pela Assembleia Legislativa do Rio Grande do Sul; a lei no 12.442 de 18 de maio de 1995, promulgada pela Assembleia Legislativa do Ceará. No caso de Alagoas, a Constituição Estadual de 1989 tornou a gestão democrática fato possível.

Entretanto, a vivência do processo democrático nas escolas públicas estaduais de Alagoas só tem início em 1999, quando os segmentos educacionais estiveram envolvidos no $I$ Congresso Constituinte, a partir de uma discussão coletiva que resultou na Carta de Princípios que representa a Constituição da Educação do Estado de Alagoas, contendo os anseios dessa construção. 
A gestão democrática no referido Estado é decorrente do processo de democratização da sociedade brasileira, referendado pela Constituição Federal de 1988. A Lei $n$ ‥ 9394/96 assegura nos artigos 14 e 15: a gestão democrática através do envolvimento dos profissionais da educação na elaboração do projeto pedagógico da escola, e da inserção das comunidades escolar e local em conselhos escolares, permitindo com isto o protagonismo dessas comunidades no campo da gestão escolar.

O processo de implantação da gestão democrática em Maceió, capital alagoana, iniciou-se bem antes, isto é, em 1993. As bases legais são: 1) a Constituição do Estado de Alagoas de 1989, no cap. III, art. 20, admitindo a competência dos Conselhos Municipais de Educação e a participação da comunidade escolar no planejamento das atividades administrativas e pedagógicas; b) a Lei Orgânica do Município de Maceió, no Art. 142, que garante a criação do conselho escolar e a realização da eleição de diretores e diretores adjuntos. De outro lado, o Estatuto do Magistério, Lei no 6.196/2001, no Art. 232, garante a participação efetiva da comunidade no processo de gestão na unidade escolar (MACEIÓ, 2001). Ao considerar toda essa realidade a presente pesquisa pretendeu mapear os principais entraves da participação na escola ao mesmo tempo em que buscou detectar as potencialidades da participação dos pais e dos alunos na gestão da escola pública.

\section{A democratização da gestão escolar: sentidos e estratégias de ação}

A questão da democracia, ao final do século $X X$, tem sido muito discutida $e$ referenciada nos estudos que tratam de políticas educacionais. Isto ocorre seja pelo fato de se configurar como anseio político das sociedades, com forte herança do Ocidente, seja por se tratar de um tema que se articula com duas outras categorias históricas fundamentais: cidadania e participação.

A democracia se contrapõe a formas de governos autocráticos, cujo poder antidialógico/antiparticipativo sobrepõe-se à vontade de discussão e à conversação das questões referentes à coletividade. Em tal perspectiva, é a democracia, por excelência, um regime de poder baseado no diálogo e na participação, isto é, todo e qualquer governo democrático não existe sem uma cultura e sem uma sociedade democrática.

Ao tratar de gestão democrática é preciso saber que a mesma é fruto de uma época, na qual a sociedade brasileira voltava a respirar (mesmo que timidamente) os ares do Estado 
democrático de direito. As lições retiradas do Estado de exceção deixaram marcas profundas na população brasileira, pois mesmo com a redemocratização, iniciada em fins da década de 1970, muitos diretores, pais, funcionários e professores vivenciaram na sociedade, na escola e na família práticas autoritárias no contexto da ditadura.

Uma sociedade autoritária, com tradição autoritária, com organização autoritária e,
não por acaso, articulada com interesses autoritários de uma minoria, orienta-se na
direção oposta a da democracia. Como sabemos, os determinantes econômicos,
sociais, políticos e culturais mais amplos é que agem em favor dessa tendência,
tornando muito difícil toda ação em sentido contrário (PARO, 1997, p. 19).

É difícil constituir uma cultura democrática da noite para o dia, visto que toda cultura é também histórica e está articulada com as crenças, valores e representações de uma dada sociedade. Apenas os preceitos da gestão democrática, instituídos na Constituição Federal de 1988 e na Lei no 9394/96, não garantem as mudanças nas práticas autoritárias, e sim, a participação ativa da comunidade escolar, especialmente dos pais e alunos.

Quanto mais a comunidade escolar participa e dialoga sobre os problemas da escola, buscando coletivamente as saídas e soluções, tanto mais rompem com uma postura autoritária por parte dos dirigentes e da sociedade. Todavia, não se pode desprezar que o marco legal da gestão democrática constituiu-se num grande avanço, considerando a realidade brasileira.

O termo gestão é relativamente jovem (data de meados da década de 1990). Anterior a ele, o termo administração aplicava-se indistintamente às empresas ou às escolas. Desse modo, a unidade escolar recebeu influência da gerência científica: "A administração escolar como disciplina e prática administrativa demonstra em seu conteúdo as características das diferentes escolas da administração de empresas, aplicando-as à atividade específica da educação" (HORA, 2007, p.35).

O termo gestão ganhou contorno de ação dinâmica, dialética e, ao mesmo tempo, flexibilidade. À passagem de um a outro vocábulo, isto é, da administração para gestão, envolveu questões como democratização, autonomia e participação. Entretanto, na observação mais atenta dos dois termos - administração e gestão - verifica-se que as acepções de ambos guardam similaridades:

A gestão é a atividade pelo qual são mobilizados meios e procedimentos para se atingir os objetivos da organização, envolvendo, basicamente, os aspectos gerenciais e técnicos - administrativos. Nesse sentido, é sinônimo de administração. (LIBÂNEO, 2004, p.101). 
No caso da terminologia, gestão tem outra dimensão, porquanto passou a vir acompanhada da palavra democrática, relacionada a uma concepção que Libâneo (2004) denomina de democrático-participativa. De outro lado, Souza (2009, p. 125) compreende ser:

[...] um processo político no qual as pessoas atuam na/sobre a escola, identificam problemas, discutem, deliberam e planejam, encaminham, acompanham, controlam e avaliam o conjunto das ações voltadas ao desenvolvimento da própria escola na busca da solução para aqueles problemas (SOUZA, 2009, p. 125).

Entre os diversos elementos que abalizam a gestão democrática, viabilizando a sua implementação, tem-se: 1) a autonomia pedagógica, em que se insere a elaboração do Projeto Político Pedagógico - PPP; 2) a autonomia administrativa e financeira, com a eleição direta para diretor e conselho escolar (WERLE, 2003). A gestão democrática provoca a participação da comunidade escolar:

A gestão democrática da escola implica que a comunidade, os usuários da escola, sejam seus dirigentes e gestores e não apenas os seus fiscalizadores ou, mesmo ainda, os meros receptores dos serviços educacionais. Na gestão democrática pais, mães, alunos, alunas, professores e funcionários assumem sua parte de responsabilidade pelo projeto da escola (GADOTTI, 2002, p.35).

Para a consolidação da autonomia administrativa, dois mecanismos de gestão democrática estão presentes no cotidiano escolar: a eleição direta para diretores, respaldada pelo voto direto da comunidade escolar, e a eleição do conselho escolar referendada pelos pares, ambos com o objetivo precípuo da melhoria da qualidade educativa.

Eleger um diretor ou um conselho não garantiu autonomia administrativa, mas foi, certamente, um passo fundamental para seu alcance: “A forma de gestão, os controles normativo-burocráticos, a racionalidade interna, administração pessoal, administração pessoal e o controle de natureza social são dimensões que podem ser medidas" (NEVES, 2007, p. 102). Escolher os diretores foi um grande marco para as escolas públicas, um acanhado passo para a democracia. No entanto, só isso não garante a gestão democrática, visto que:

[...] as pessoas que pensavam que, com as eleições, o diretor mudaria seu comportamento de forma radical e imediata, frustraram-se ao perceber que muito das características do chefe monocrático que detém a autoridade máxima na escola persistiu mesmo com a eleição (PARO, 2001, p. 67). 
Apesar das eleições não garantirem práticas democráticas, essas têm sido referendadas pela comunidade escolar. $O$ que se coloca como imperativo na gestão democrática é a participação. Faz-se necessário abordar o que é participação; princípios de participação e os tipos de participação que configuram a gestão participativa democrática; como, também, as barreiras encontradas para que ela aconteça de fato na escola pública, envolve toda uma complexidade do entendimento do que seja, na verdade, participar.

A participação ocorre em todos os meios sociais, na família, templos religiosos, clubes, escola e outros. Mas, existem diferentes formas de participação, ao frequentar um lugar, estar de corpo presente não significa que você esteja participando, e, sim, presente no local. A participação exige algo mais, como emitir opiniões, envolver-se com o processo, interferir, ouvir e aceitar as ideias do outro. A questão da participação pode ser entendida como:

[...] uma conquista para significar que é um processo, no sentido legítimo do termo: infindável, em constante vir- $a$-ser, sempre se fazendo. Assim, participação é em essência autopromoção e existe enquanto conquista processual. Não existe participação suficiente, nem acabada (DEMO, 1996, p. 18).

A participação se dá por uma conquista e pela vivência, em que as pessoas ocupam os espaços e experimentam situações de envolvimento: ninguém nasce sabendo participar, mas vivenciando situações em que esta ação se faça presente: “A participação não pode ser entendida como dádiva, como concessão, como algo já preexistente" (DEMO, 1996, p. 18).

No final da década de 1970, os movimentos sociais e populares lutavam por um país mais democrático, diferentes entidades exigiam mais oportunidade de participação na sociedade, o que acarretou, no início da década de 1980, ações práticas que encadearam a legitimação de leis com princípios democráticos. Nesse sentido, foi aprovada a lei federal 7.398/85, que recriou o grêmio estudantil dentro da escola, definindo-o como órgão representativo do corpo discente de cada unidade escolar cuja finalidade é a de favorecer o desenvolvimento da consciência crítica, da prática democrática, da criatividade e da iniciativa juvenil (BRASIL, 1985). Por sua vez, os alunos:

[...] reconhecem como pertinentes ao grêmio: o debate, a participação nas decisões, a escolha da representatividade, a comunicação entre os membros da comunidade escolar, o exercício do trabalho coletivo, valorização da cultura e a autonomia do grupo (GRÁCIO; AGUIAR, 2002, p. 74).

A participação representativa é válida quando ocorre o acompanhamento sistemático dos representados por seus representantes, não é simplesmente elegê-los e delegar total 
responsabilidade da realização das propostas definidas. Na história das escolas, quantos professores, diretores, funcionários, alunos e pais se desmotivaram em lutar por mais participação? No entanto, é imprescindível que a escola não desista de trilhar um processo democrático.

Não se pode mudar a realidade com a rapidez com que se concebe uma mudança. São ações continuadas e sucessivamente realizadas que vão construindo, no tempo, a mudança maior. Assim, uma prática escolar democrática e participativa se estabelece a partir de ações e de estratégias simples, mas orgânicas, com direção bem clara (GANDIN, 1998, p. 95).

Há um equívoco muito grande quando se fala da participação dos pais ou responsáveis, para muitos gestores escolares tal participação concretiza-se em prestar serviços como limpeza de sala, pequenos reparos na estrutura da escola. Enfim, trabalhar voluntariamente na unidade escolar. Entretanto, tais ações competem ao Estado realizar, e não à comunidade escolar.

Nesse processo de formação, deve ocorrer a junção de alunos, pais e todos que atuam na escola, eles não podem ser considerados de forma isolada. Assim: "Não qualquer participação, mas a participação que permite aos cidadãos influenciar/tomar parte do poder, ter parte na deliberação e tomada de decisões públicas" (FREITAS, 2007, p. 514). Não se pode falar de democracia se não há participação, a primeira só se concretiza com a atuação da segunda, pois ambas se completam.

\section{Paisagens metodológicas e resultados em análise}

A pesquisa caracterizou-se como de natureza qualitativa, por considerar que corresponde à forma mais satisfatória de abordagem do objeto de estudo, visto que tratamos de sentidos e significados, com o intuito de descobrir o ambiente escolar, as relações, características e os discursos dos indivíduos que pertencem a esse ambiente para uma posterior análise crítica.

Os procedimentos qualitativos apresentam um grande contraste com os métodos
de pesquisa quantitativa. A investigação qualitativa emprega diferentes alegações
de conhecimento, estratégias de investigação e métodos de coleta e análise de
dados. Embora os processos sejam similares, os procedimentos qualitativos se
baseiam em dados de texto e imagem, têm passos únicos na análise de dados e
usam estratégias diversas de investigação (CRESWELL, 2007, p. 184).

O que se buscou nesta pesquisa - com observações e interpretações feitas no contexto das interações humanas - foi investigar como se dá a participação dos pais e alunos 
nos espaços criados pela escola. Para tanto, partiu-se do universo da rede pública municipal de Maceió, composto de 128 (cento e vinte e oito) unidades escolares, divididas em 8 (oito) regiões administrativas. Os critérios para a seleção das escolas foram: capacidade de atendimento (escolas com mais de 600 matrículas); níveis de escolaridade oferecidos (escolas que contemplassem do 1 으 ao 9o ano); localização (bairros periféricos e bairros centrais) e tempo de funcionamento (mais de cinco anos e onde já tivesse ocorrido eleição direta para a equipe gestora).

Foram escolhidas 26 escolas, organizadas em duas categorias: médio e grande porte e região administrativa. Uma segunda seleção reduziu o campo de pesquisa para 4 (quatro) unidades escolares, considerando o tempo e a exequibilidade da pesquisa. Os sujeitos foram convidados a participar e a contribuir com suas opiniões acerca do objeto investigado. Para a seleção de pais, foram eleitos aqueles que mais compareceram à escola ou que atuaram no conselho escolar. Para a seleção dos alunos, considerou-se os que atuaram como representantes de turma e cursavam do 60 a a 9 음 ano.

O instrumento utilizado foi o grupo focal com pais e alunos, uma forma de ouvir alguns segmentos da escola, atentando para as especificidades assim como para as características análogas. Foram selecionados 7 (sete) a 10 (dez) pais e alunos, em grupos separados. Essa técnica possibilitou a escuta de diversas falas, que contribuíram de forma significativa para a análise dos dados.

[...] é importante o respeito ao princípio da não diretividade, e o facilitador ou moderador da discussão deve cuidar para que o grupo desenvolva a comunicação sem ingerências indevidas da parte dele, como intervenções afirmativas ou negativas, emissão de opiniões particulares, conclusões ou outras formas de intervenção direta (GATTI, 2005, p.8).

Na condução do grupo cuidou-se para não influenciar a opinião dos participantes. Procurou-se fazer questionamentos, caso o grupo não avançasse ou mudasse de tema, envolvendo outras questões não solicitadas, o moderador do grupo focal assume uma “(...) posição de facilitador do processo de discussão, e sua ênfase está nos processos psicossociais que emergem, no jogo de interinfluências da formação de opiniões sobre um determinado tema" (GONDIM, 2002, p. 151).

Problematizou-se a gestão participativa na perspectiva dos pais e alunos da escola. Para uma análise das falas dos sujeitos, foram elencadas as categorias de acordo com os 
elementos do grupo focal. Nesse contexto, expuseram-se duas questões: como ocorre a participação e como a mesma fortalece o conselho?

Na escola A, o grupo focal foi formado por 7 alunos do turno noturno, que frequentavam do 6으 ao 9 을 ano, sem um roteiro de perguntas, apenas era lançada uma questão chave para que falassem sobre ela. Desse modo, os alunos se pronunciavam ${ }^{1}$.

Fazia parte do grupo um aluno do conselho escolar que, em relação à primeira situação, isto é, a participação, assim se referiu: Só pelo fato de ter reuniões não garante a participação (Dayvid).

Os demais alunos o ouviram atentamente, e colocaram que isso é verdade, no que ele assentou: Não só o conselho tem que ter reuniões, mas assim, a diretora também falar com os alunos (Dayvid).

Esse aluno deixou clara a dificuldade da direção da escola em dialogar com os alunos. E acrescentou: Também valeria a pena, pelo menos ouvir nossa opinião, porque somos pessoas diferentes, temos ideias diferentes, nós observamos coisas diferentes, então cada um de nós tem uma opinião aqui sobre a escola (Dayvid).

Pela fala do aluno e pela concordância dos demais com relação à sua opinião, percebemos que os mesmos (alunos) se sentem discriminados, pois não são escutados pela direção. Outra aluna argumentou: Eu queria ser mais ouvida (Bruna).

Muitos alunos no grupo focal colocaram-se, dizendo que gostariam, simplesmente, de serem ouvidos. Nesses comentários compreendeu-se que os alunos necessitavam ser escutados, entretanto não eram percebidos pela direção como um segmento que podia contribuir com a gestão. A partir dos depoimentos percebeu-se que, nesse caso, a direção pouco dialoga com os alunos, por acreditar na passividade dos mesmos.

Edileia adicionou: Nunca procurei a direção, às vezes eu fico com receio, porque a gente não ver mudança, aí não procuro.

E Cícera também se colocou: Procurava a direção, mas ela não se importava, deixei de procurar ela.

Se a escola reclama do fato de que o aluno não tem interesse, parece que isso é muito mais uma reação deste à situação de insignificância vivida no interior escolar. É preciso que os gestores entendam a quem estão servindo ou formando. Então, como

\footnotetext{
${ }^{1}$ Por questões éticas os nomes utilizados para os sujeitos da pesquisa são fictícios.
} 
desenvolver o senso crítico dos alunos, senão oportunizando momentos de participação democrática?

É necessário que a escola se relacione mais com seus alunos, afinal: ela existe para atender a quem? Qual sua função social? Os princípios democráticos se voltam para a ampla participação de todos, inclusive dos alunos, para que eles possam ser sujeitos capazes de defender seus direitos, e isso não está acontecendo dentro da escola pública maceioense, isso é tão notório que os alunos que participaram do grupo focal nunca ouviram falar sobre o grêmio estudantil.

Essa análise realizada não diferiu muito da escola B, grupo de alunos do 6으 ao 9음 ano, período noturno, os alunos também sentiam necessidade de participarem nos espaços de decisão dentro da escola. Segundo eles, a mesma promove reuniões com os alunos, mas:

\begin{abstract}
Nunca sai o assunto que a gente quer, porque às vezes como ela falou (a aluna anterior), existe violência na sala, professor que não dá aula. Quando a diretora requisita reunião é só pra falar o quê? De verbas, de contas da escola. Quer mostrar que tá tudo em dia [...] (DAYVID).
\end{abstract}

$\mathrm{Na}$ escola, as reuniões limitam-se a comunicar a promoção de palestras, que, segundo os alunos: A gente nem sabe o tema; é obrigado a assistir; as palestras são como se não existissem, não acrescentam nada para nosso desenvolvimento; o som é péssimo, não dá pra ouvir, entender nada (DAYVID).

Apesar de a escola promover atividades diferentes, os alunos não participavam desse planejamento, apenas eram comunicados e obrigados a participar dessas ações que, por não entenderem seus objetivos, resultavam em muitas críticas à escola.

Os alunos viam a escola como organizada, um bom ensino e muito segura, nesses aspectos elogiavam e relatavam que gostariam que a escola oferecesse até o ensino médio para continuarem, mesmo achando a direção muito rígida.

Em relação à função de representante de turma, não havia a atitude de colocar os nomes no papel, mas sua ação se limitava a dedurar à direção os alunos que não tinham interesse nas aulas e não deixavam o professor dar sua aula. Os representantes denunciaram que procuravam conversar com a turma, mas não eram ouvidos: Eu fui representante de turma no quinto ano e estou sendo de novo no sexto, mas é tapem os ouvidos, fechem os olhos e calem a boca (BRUNA). 
Sentiam a necessidade de momentos com a direção para falar de assuntos da sala de aula, mas não encontravam espaços. Também, como na outra escola, as dificuldades apontadas recaíram sobre a sala de aula, principalmente em relação aos professores, sentiam-se sozinhos e sem assistência para o seu aprendizado.

Diferente das características dos grupos da escola A e B, na escola C formaram-se grupos focais com alunos, representantes de sala, do 60 ao 9o ano do turno diurno, com idade de 12 a 17 anos. Ao tratar sobre a função de representante de turma, as atitudes dos alunos se resumiam a escrever no papel os nomes daqueles que estavam bagunçando na sala ou quebrando algo. Diante dessa atitude, sofriam ameaças dos próprios colegas: Eu fico olhando os meninos que bagunçam dentro da sala, e anoto o nome, só que quando vou anotar os nomes, os meninos dizem que vão me pegar (DAYVID).

Ao trabalhar com representantes de turma percebeu-se que eram responsáveis por denunciarem aqueles que cometiam pequenos delitos. Uma situação delicada que prejudicava a interação com o outro, e, em caso mais grave, ameaçava a segurança dos próprios representantes. A função do representante precisa ser debatida, trabalhar a questão da representatividade em sala de aula, em que o representante junto à direção discute questões que envolvem a sala de aula.

No que se refere à questão da participação, eles pouco participavam, geralmente as normas eram determinadas pela direção, mas que para eles precisavam ser cumpridas por todos. Bruna explicou: Se tem uma lei, tem que botar para todo mundo cumprir.

E acrescentou: As diretoras têm que tomar atitudes para que as leis sejam cumpridas.

A representante de turma reclamou que, em alguns momentos, havia certa flexibilidade com alguns, deixando-a indignada.

Como na escola C, na escola D também foram ouvidos os alunos do diurno, da mesma faixa etária. Em alguns momentos, houve necessidade de outros questionamentos, pois eles tinham dificuldades em expor suas ideias; foi preciso, também, interferências para que eles retornassem ao assunto.

Em relação ao envolvimento deles na escola, foi possível constatar que, de maneira geral, a escola não oferecia muitas atividades para que houvesse a interação e a participação do aluno. Os alunos comentavam sobre os passeios, como uma atividade muito interessante e necessária, mas discordavam de não ser acessível para todos e da forma como os alunos 
eram selecionados. Segundo eles havia uma seleção de dois alunos por turma, tendo alguns critérios com base no comportamento.

Esses alunos expunham os projetos desenvolvidos pela escola, mas relatavam que muitos eram cancelados pela indisciplina dos alunos, como por exemplo: a festa junina. Fatos como esse os deixava desestimulados, e criticavam essa postura da escola, acreditando que esse tipo de punição não é o caminho correto para lidar com os problemas de indisciplina.

Nessa escola não tinha grêmio estudantil, os alunos que fizeram parte do grupo eram representantes de turma e as pesquisadoras solicitaram que falassem de como é ser representante de turma. Eles revelavam a dificuldade de conseguir manter a sala disciplinada e dos seus colegas os respeitarem, como também aos professores. Viam a função de representante como responsável em manter a ordem na sala, e ficavam decepcionados por não conseguirem. Sentiam, a semelhança das outras escolas, a necessidade de ser ouvidos.

Outro segmento ouvido foram os pais, e, assim como a análise com os alunos, também foram observadas as categorias, elencando cada escola. Na escola $\mathrm{A}$ os pais que participaram do grupo focal tinham filhos matriculados do 1 을 a 50 anos, nenhum desses faziam parte do conselho da escola, mas sempre estavam presente na escola, os acompanhando.

Em relação à questão de como pode ocorrer a participação, eles se colocavam como participantes ativos, porque sempre estavam acompanhando os seus filhos, e conversando com os professores, mas sentiam a ausência dos outros pais, como enfatizou Socorro: $A$ comunidade aqui em geral não participa da escola, não há essa integração que poderia haver com mais intensidade.

Maria Cícera acrescentou: As mães tem que ser participativa, tem que vim mais para as reuniões; e também independente da reunião a mãe tem que estar presente na vida do aluno.

Assim como os alunos entrevistados na escola, as mães também enfocaram a não participação dos outros pais na vida dos seus filhos, de tanto ouvir da escola as mesmas reclamações, os que frequentam assiduamente a escola terminavam por ter um mesmo discurso, até quando se referia ao seu próprio segmento. As dificuldades apresentadas pelos 
alunos recaiam sobre os pais que não os acompanhavam, isentando a escola dessa responsabilidade.

Percebeu-se que a participação dos pais ocorria através da ajuda de serviços à escola: Fazer algum trabalho aqui no colégio nunca fiz não, assim ajudar aqui em alguma coisa, na merenda, porque tem vez que tem mãe que é convidada para merenda, assim, ajudar na cozinha. Eu nunca fui chamada para nada disso não (SOCORRO).

Essa visão, mais uma vez, refletia na forma como eles eram tratados na escola, em que momentos eles eram convidados a participar.

Os oito pais da escola B que participaram tinham filhos do 1을 5 o anos, nenhum deles faziam parte do conselho. Igualmente como a escola $A$, esses pais também demonstraram dificuldade em expor uma concepção de participação, também a viam como estar diariamente na escola para acompanhar seus filhos, uma visão frágil e limitada de participação.

Gostavam do ensino da escola, mas também reclamavam da falta de estrutura: $a$ escola deveria oferecer para os alunos dias educativos, como: brincar, educação física, jogos, porque eles ficam sempre na sala escrevendo (MARIA CÍCERA).

E Marilene completou: É uma escola excelente, mas precisa de atividades diferentes.

Nesse contexto, percebe-se que havia uma consciência do que gostariam que tivesse para seus filhos: uma escola de qualidade. As ações citadas não se diferenciavam em relação à escola A. Esse grupo de pais apresentou muitas dificuldades em falar sobre a participação na escola, sentiam necessidade de reivindicar por melhorias na escola. Por mais que voltassem ao questionamento inicial, os pensamentos deles seguiam a necessidade de melhorar o ambiente escolar para seus filhos.

A partir dessa análise, verificou-se como havia uma carência na escola de momentos de participação, nos quais os pais tenham voz, pois eles têm noção do que é melhor para os seus filhos e poderão contribuir para reivindicar uma escola com uma melhor estrutura e um ensino de qualidade.

Já o grupo focal de pais da escola C, foi composto por 7 (sete) mães, sendo que duas integravam o conselho escolar. Estas, atuantes e bastante participativas nas questões que envolviam a escola, desde o acompanhamento aos alunos a passeios à limpeza dos banheiros, ações de ajuda na escola. Foi interessante observar como essas mães que 
atuavam no conselho se posicionavam da mesma forma que a direção, ou seja, culpavam os pais pelos problemas dos filhos, e os criticavam por não ajudar a escola: Os pais participem na escola, que precisou a escola de alguma ajuda, não espere pelo governo, nem pela SEMED, participar de tudo na escola, na limpeza, nos problemas fundamentais (MARILENE).

A escola cometeu o mesmo equívoco de que participar era ajudar com mão de obra, serviços que se constituem como sendo de obrigação do órgão mantenedor, recaíam na responsabilidade dos pais, eximindo-se tal órgão de cumprir com suas funções.

Para finalizar, o grupo de pais da escola D, composto por 6 mães e 1 pai. Das mães, duas fazem parte do conselho escolar. No que diz respeito à participação, Sandra comentou: Não pode ser do nosso jeito, mas combinando com todo mundo.

E Edmerson apôs que: Tudo que é feito é para os alunos, que sejam beneficiados em todos os aspectos.

Em relação de como percebiam a participação, Sandra enfatizou: Qualquer manifestação em prol da escola estamos sempre presentes.

E emendou: Há uma divisão do grupo, um que ajuda com trabalhos na escola e outro que elabora os manifestos e documentos com reivindicações para os órgãos responsáveis.

Observou-se que eles percebiam mais como uma participação política de reivindicação, pois devido aos inúmeros problemas enfrentados pela escola, principalmente em relação à falta de professores, os pais que faziam parte do conselho encontraram alternativas para sanar esses problemas que afligiam a escola, recorrendo a órgãos de instância jurídica. Foi com essas atitudes que eles lograram êxito, resolvendo, depois de manifestações públicas e documentos no ministério público, o problema da falta de professores.

Os pais viam a escola como a melhor do bairro, elogiando o fato de a escola estar sempre aberta para eles, com acesso à direção, onde eram bem recebidos, sentiam liberdade em tomar decisões dentro da escola, no caso dos pais que participavam do conselho escolar.

Os pais elencaram uma série de entraves que dificultavam as ações na escola: não havia momento de discussão entre os pais, falta de participação nas reuniões e plantões pedagógicos; descaso do gestor maior com a educação; mudança constante de secretários 
da educação; interesses político-partidários, não havia atendimento à escola por parte dos órgãos responsáveis por resolver problemas estruturais na escola, só com pressão.

Verificou-se, nesse grupo, uma maior politização em relação às reivindicações para a escola, o mesmo possuía consciência de que é necessário lutar para garantir o direito a uma educação de boa qualidade, não ficavam esperando, procuravam agir com atitudes fundamentadas e coerentes. Entretanto, isso só ocorria quando surgiam problemas sérios, não era uma prática constante na busca da melhoria do ensino.

\section{Considerações finais}

A gestão democrática pode ser entendida como forma de gerenciamento da escola pública que pode instaurar um espaço de participação, de desconcentração do poder e do exercício da cidadania por meios de mecanismos de participação, como: a escolha dos dirigentes escolares, o Conselho Escolar, o Conselho de Classe, a Associação de Pais e Mestres, Grêmio Estudantil, entre outros. A gestão democrática supõe a autonomia dos sistemas que devem definir suas formas, atentando para as peculiaridades locais e a participação da comunidade na proposta pedagógica nas instituições de ensino.

$\mathrm{Na}$ análise crítica dos espaços de participação democrática, havia toda uma conjuntura que remetia ao fato de que a gestão democrática ainda não era algo concreto nas escolas públicas de Maceió, na escola ocorriam espaços de participação, mas da forma que aconteciam não eram exercícios democráticos, pois não havia o envolvimento nas tomadas de decisões dos que atuavam na escola e nem dos que a frequentavam. A postura centralizadora ainda era dominante dentro da escola. Por sua vez, os envolvidos nesse processo não reivindicavam esses espaços e se mostravam passivos diante da situação.

Dentre as 4 (quatro) escolas pesquisadas, nenhuma possui o grêmio estudantil; nas escolas C e D já houve algumas ações para sua implantação, mas que não foram concretizadas, e nas escolas $A$ e $B$ os alunos não tinham conhecimento do que se tratava. Tem todo um suporte legal para o Grêmio Estudantil atuar, mas como não há um real envolvimento dos estudantes não há uma evolução nesse sentido.

Nas escolas pesquisadas, chegou-se à constatação de que a participação dos estudantes e dos pais ainda é um processo que precisa ser conquistado e construído, visto que ambos desconheciam como se davam o funcionamento e a organização dos processos 
democráticos. Nesse sentido, a quem interessa não ter estudantes participativos e pais presentes na escola? O que aconteceria se houvesse um olhar mais crítico sobre a qualidade da escola pública? É preciso ter claro qual o interesse de não ocorrer, nas escolas, esses movimentos. Por sua vez, a escola precisa ser consciente da importância de formar estudantes mais críticos para tê-los como aliados na busca por espaços mais democráticos.

\section{Referências}

ALAGOAS. Governo do Estado. Gabinete Civil. Constituição do Estado de Alagoas. GOMES, F.L.; BARROS, F.A.C. de; LEAHY, M.O. (Orgs.). Maceió: Secretaria de Educação do estado de Alagoas, 2004. Disponível em: <www.portaldoservidor.al.gov.br>Acesso em: 26 nov. 2009.

BRASIL. Constituição da República Federativa do Brasil: Texto Constitucional promulgado em 05 de outubro de 1988. Brasília: Senado Federal, Subsecretaria de Edições Técnicas, 2006.

BRASIL. Palácio do Planalto. Lei № 9.394/96, 20 de dezembro de 1996. Estabelece as Diretrizes e Bases para a Educação Nacional. Disponível em: http://www.planalto.gov.br/ccivil 03/leis/l9394.htm. Acesso em: 13 set. 2008.

BRASIL. Palácio do Planalto. Lei 7.398, 4 de novembro de 1985. Dispõe sobre a criação de grêmios estudantis. Disponível em http://www.planalto.gov.br/ccivil 03/leis/L7398.htm. Acesso em 03 de dezembro.

BRASIL. Palácio do Planalto. Lei 10.172. 9 de janeiro de 2001. Dispõe sobre o Plano Nacional de Educação. Disponível em http://www.planalto.gov.br/ccivil 03/leis/L7398.htm. Acesso em 03 de dezembro. Acesso em: 13 set. 2008.

CEARÁ. [Estado]. Governo do Estado do Ceará. Lei 12.442, de 18 maio de 1995. Dispõe sobre a Gestão Democrática do Ensino Público e dá outras providências. Disponível em: http://www.al.ce.gov.br/legislativo. Acesso em: 25 jul. 2013.

CRESWELL, J. Projeto de pesquisa: métodos qualitativo, quantitativo e misto. 2. ed. Porto Alegre: Bookmann, 2007.

DEMO, P. Participação é conquista: noções de política social e participativa. 3. ed. São Paulo: Cortez, 1996.

RIO GRANDE DO SUL. [Estado]. Assembleia Legislativa. Gabinete de Consultoria 
Legislativa. Lei no 10.576, de 14 de novembro de 1995. Dispõe sobre a Gestão Democrática do Ensino Público e dá outras providência. Disponível em: http://www.educacao.rs.gov.br/dados/lei 10.576 compilado.pdf. Acesso em: 25 jul. 2013.

FREITAS, D. N. T. Avaliação e gestão democrática na regulação da educação básica brasileira: uma relação a avaliar. Educ. Soc. , Campinas, v. 28, n. 99, p. 501-521. 2007. Disponível em: $<$ http://www.scielo.br/scielo.php?script=sci_arttext\&pid $\quad$ =S0101$73302007000200011 \& \operatorname{lng}=\& n r m=i s o>$. Acesso em: 21 out. 2007.

GADOTTI, M. "Projeto Político- Pedagógico da Escola - Fundamentos para a sua realização". In ROMÃO, J.E. (Orgs.). Autonomia da escola: princípios e propostas. 5. ed. São Paulo: Cortez, 2002.

GANDIN, D. Escola e transformação social. 5. Ed. Petrópolis: Vozes, 1998.

GATTI, B. A. Grupo Focal na pesquisa em Ciências Sociais e Humanas. Brasília: Liber Livro, 2005.

GONDIM, S. M. G. Grupos focais como técnica de investigação qualitativa: desafios metodológicos. Paidéia, Ribeirão Preto, v. 12, n.24, p. 149-161.2002. Disponível em: http://www.scielo.br/pdf/paideia/v12n24/04.pdf. Acesso em: 21 out. 2007.

GRÁCIO, J.C.; AGUIAR, R. C. Grêmio Estudantil: construindo novas relações na escola. In: BASTOS, J.B. (Org.) et al. Gestão democrática. 3. ed. Rio de Janeiro: DP\&A; SEPE, 2002. p. 22-43.

HORA, D. L. Gestão Educacional Democrática. Campinas: Alínea, 2007.

LIBÂNEO, J. C. Organização e gestão na escola: teoria e prática. 5. ed. Campinas: Alternativa, 2004.

MACEIÓ [Município]. Câmara Municipal de Maceió. Lei no 6.196, 28 de setembro de 2001. Estatuto do Magistério. Disponível em: http://www.jusbrasil.com.br/diarios/32005783/doeal-executivo-0411-2011-pg-10. Acesso em: 27 nov. 2010.

MACEIÓ [Município]. Câmara Municipal de Maceió. Lei Orgânica do Município de Maceió, 31 DE MARÇO DE 2003. Disponível em: https://www.leismunicipais.com.br/lei-organica/maceio-al/77. Acesso em: 25 nov. 2009.

NEVES, C. M. C. Autonomia da escola pública: um enfoque operacional. In: VEIGA, I.P.A. (Org.). Projeto político-pedagógico da escola: uma construção possível. 23. Ed. Campinas: Papirus, 2007. p. 95-129. 
PARO, V. H. Escritos sobre educação. São Paulo: Xamã, 2001.

PARO, V. H. Gestão democrática da escola pública. São Paulo: Ática, 1997.

SOUZA, Â. R. Explorando e Construindo um Conceito de Gestão Escolar Democrática. Educação em Revista, Belo Horizonte, v. 25, n.03, p.123-140, dez. 2009.

TAVARES, M. G. M. Educação brasileira e negociação política: o processo constituinte de 1987 e gestão democrática. Maceió: Edufal, 2003.

WERLE, F. O. C. Conselhos Escolares - implicações na gestão da Escola Básica. Rio de Janeiro: DP\&A, 2003.

Enviado em Junho/2013

Aprovado em Novembro/2013 